\title{
PENYISIHAN LOGAM DALAM LIMBAH CAIR KERAJINAN TENUN SONGKET DENGAN METODE ELEKTROKIMIA
}

\author{
Atikah \\ Fakultas Teknik, Universitas Muhammadiyah Palembang \\ email : the_lumos@yahoo.com
}

\begin{abstract}
Abstrak
Kerajinan tenun songket yang ada di Kota Palembang menghasilkan limbah cair yang berasal dari proses pewarnaan yang umumnya menggunakan pewarna sintetis. Limbah yang dibuang tanpa pengolahan sebelumnya akan melewati perairan menuju ke Sungai Musi, oleh karena itu perlu dilakukan pengolahan limbah lebih lanjut agar limbah ini aman bagi lingkungan perairan. Penelitian ini bertujuan untuk mengurangi kadar logam pada limbah cair kerajinan tenun songket sehingga dapat mengurangi beban pencemaran pada perairan Sungai Musi. Parameter yang diamati adalah perubahan kadar logam Zn dan $\mathrm{Fe}$. Penelitian dilakukan pada skala laboratorium secara batch dengan menggunakan lempengan aluminium berukuran 24, 32 dan $40 \mathrm{~cm} 2$ sebagai elektroda. Variasi dilakukan pada waktu dan ukuran lempengan. Tegangan listrik yang digunakan adalah 12 volt dengan kuat arus 0.5 ampere. Jarak elektroda yang digunakan $5 \mathrm{~cm}$. Sampel diambil pada 20, 30, 40, 50 dan 60 menit sejak elektroda mulai dialiri arus listrik. Analisa sampel dilakukan setelah sampel terlebih dahulu diendapkan selama 30 menit. Hasil analisa menunjukkan persentase penurunan kadar Fe tertinggi mencapai $94.14 \%$ dengan kadar $0.15 \mathrm{mg} / \mathrm{L}$ terjadi pada menit ke 60 dengan ukuran lempengan elektroda $40 \mathrm{~cm}^{2}$. Kondisi terbaik untuk $\mathrm{Zn}$ terjadi pada waktu 60 menit dan luas lempengan elektroda $40 \mathrm{~cm}^{2}$ dimana penurunan $\mathrm{Zn}$ sebesar $98.04 \%$ dengan kadar $0.02 \mathrm{mg} / \mathrm{L}$.
\end{abstract}

Kata kunci : limbah cair, tenun songket, logam, elektrokimia

\section{PENDAHULUAN}

Keberadaan kerajinan tekstil di Indonesia tidak hanya dalam kategori kerajinan skala besar dan menengah tetapi juga dalam skala kecil bahkan ada yang dalam skala rumah tangga seperti kerajinan tenun songket yang ada di Kota Palembang. Pembuatan kain songket membutuhkan proses pewarnaan yang umumnya menggunakan pewarna sintetis. Penggunaan zat pewarna sintetis pada pembuatan kain songket akan membawa dampak pada peningkatan jumlah bahan pencemar dan limbah yang dihasilkannya. Setelah proses pewarnaan selesai akan dihasilkan limbah cair yang berwarna keruh dan pekat yang selain mengandung zat warna juga mengandung bahan-bahan sintetik yang sukar larut atau diuraikan.

Umumnya kerajinan tenun songket ini dilakukan oleh perajin yang berada di kawasan perkampungan padat penduduk. Jika kerajinan tersebut membuang limbah cair maka aliran limbah tersebut akan melalui perairan di sekitar pemukiman yang menuju ke Sungai Musi. Kondisi yang ada di lapangan menunjukkan sebagian besar limbah tidak diolah terlebih dahulu sebelum dibuang ke aliran sungai. Kalaupun ada pengolahan hanyalah pengendapan biasa dengan demikian mutu lingkungan perairan 
sungai dikhawatirkan menjadi turun. Oleh karena itu perlu dilakukan pengolahan limbah lebih lanjut agar limbah ini aman bagi lingkungan perairan Sungai Musi sebagai badan penerima cemaran.

Salah satu metode alternatif pengolahan limbah cair adalah metode elektrokimia yang memiliki beberapa keuntungan diantaranya dari segi biaya tidak mahal karena disamping alat yang sederhana juga menggunakan bahan yang selalu dapat diperbarui. Energi listrik yang digunakan pun relatif kecil karena hanya menggunakan arus listrik searah. Metode elektrokimia membantu penghilangan senyawa organik dan senyawa anorganik yang ada di dalam limbah kerajinan tenun songket.

Penelitian ini bertujuan untuk mengurangi kadar logam $\mathrm{Zn}$ dan Fe pada limbah cair kerajinan tenun songket sehingga dapat mengurangi beban pencemaran pada perairan Sungai Musi. Permasalahan pada penelitian ini adalah bagaimana mendapatkan kondisi operasi optimum pada pengolahan limbah cair kerajinan tenun songket secara elektrokimia dengan parameter waktu dan ukuran lempengan dan bagaimana perubahan kadar logam $\mathrm{Zn}$ dan Fe pada limbah setelah melalui pengolahan dengan metode elektrokimia. Penelitian ini diharapkan dapat memberikan teknologi alternatif untuk mengolah limbah cair industi tenun songket.

\section{Limbah Cair Kerajinan Tenun Songket}

Salah satu proses dalam kerajinan tenun songket yang menghasilkan limbah cair adalah proses pemberian warna atau dyeing yang di samping memerlukan bahan kimia juga memerlukan air sebagai media pelarut. Ini menyebabkan pengendalian dampak lingkungan kerajinan tekstil umumnya terfokus pada limbah cair karena memberikan dampak yang paling luas. Sebagian zat-zat yang diperlukan pada proses pemberian warna tersebut teradsorpsi oleh bahan tekstil dan tetap akan berada dalam tekstil sampai proses selesai, sedangkan sisanya berada dalam larutan dan akan terbuang bersama air bekas proses basah. Zat-zat dalam air buangan tersebut berpotensi menimbulkan masalah pencemaran lingkungan (Effendi,2000).

Karakteristik utama dari limbah kerajinan tekstil adalah tingginya kandungan zat warna sintetik, yang apabila dibuang ke lingkungan tentunya akan membahayakan ekosistem perairan. Limbah cair kerajinan tenun songket dapat dengan mudah dikenal karena warnanya. Warna selalu jadi kontaminan pertama pada limbah cair. Limbah kerajinan yang berwarna tidak hanya menimbulkan polusi secara visual, tetapi dapat meningkatkan resiko kerusakan lingkungan dan kesehatan (Cascio, 1994). Karakteristik fisik maupun kimia limbah cair dari proses pewarnaan memberikan dampak negatif terhadap lingkungan. Karakteristik kimia limbah cair meliputi senyawa organik dan senyawa anorganik. Senyawa organik adalah karbon yang dikombinasi dengan satu atau lebih elemen-elemen lain $(\mathrm{O}, \mathrm{N}, \mathrm{P}, \mathrm{H})$. Saat ini terdapat lebih dari dua juta senyawa organik yang telah diketahui. Senyawa anorganik terdiri atas semua kombinasi elemen yang bukan tersusun dari karbon organik. Karbon anorganik dalam air limbah pada umumnya terdiri atas sand, grit, dan mineral-mineral, baik suspended maupun dissolved. Misalnya: klorida, ion hidrogen, nitrogen, fosfor, logam berat dan asam.

Proses pewarnaan dan pembilasan menghasilkan air limbah yang berwarna dengan COD tinggi dan bahan-bahan lain dari zat warna yang dipakai, seperti fenol, sulfida dan logam. Zat warna ini berasal dari sisa-sisa zat warna yang tak larut dan juga dari kotoran yang berasal dari serat alam.Zat warna selain mengganggu keindahan, beberapa juga dapat bersifat racun dan sukar dihilangkan selain itu resisten terhadap degradasi saat nantinya sudah memasuki perairan (Effendi, 2003). Meningkatnya kekeruhan air karena adanya polusi zat warna, nantinya akan menghalangi masuknya cahaya matahari ke dasar perairan dan mengganggu keseimbangan proses fotosintesis, ditambah lagi adanya efek mutagenik dan karsinogen dari zat warna tersebut, membuatnya menjadi masalah yang serius (Eckenfelder,2000). 


\section{Pencemaran Logam di Lingkungan}

Pencemaran logam berat cenderung meningkat sejalan dengan meningkatnya proses industrialisasi. Pencemaran logam berat dalam lingkungan perairan, tanah maupun udara bisa menimbulkan bahaya bagi kesehatan. Logam berat dibagi ke dalam dua jenis (www.prenzi.com) yaitu :

1. Logam berat esensial, yakni logam dalam jumlah tertentu yang sangat dibutuhkan oleh organisme. Dalam jumlah yang berlebihan, logam tersebut bisa menimbulkan efek toksik. Contohnya adalah $\mathrm{Zn}, \mathrm{Cu}, \mathrm{Fe}, \mathrm{Co}, \mathrm{Mn}$ dan lain sebagainya.

2. Logam berat tidak esensial, yakni logam yang keberadaannya dalam tubuh manusia masih belum diketahui manfaatnya, bahkan bersifat toksik seperti $\mathrm{Hg}, \mathrm{Cr}, \mathrm{Cd}, \mathrm{Pb}$ dan lain sebagainya.

Logam berat masuk ke dalam jaringan tubuh makhluk hidup melalui beberapa jalan, yaitu saluran pernapasan, pencernaan, dan penetrasi melalui kulit. Absorbsi logam melalui saluran pernapasan cukup besar, baik pada biota air yang masuk melalui sistem pernafasan, maupun biota darat yang masuk melalui debu di udara ke saluran pernapasan. Logam berat dapat menimbulkan efek gangguan terhadap kesehatan manusia. Efek toksik dari logam berat mampu menghalangi kerja enzim sehingga mengganggu metabolisme tubuh, menyebabkan alergi, bersifat mutagen, teratogen, ataupun karsinogen. Karena itu pencemaran logam berat dalam lingkungan perairan, tanah dan udara perlu diperhatikan secara serius mengingat bahaya yang ditimbulkan terhadap kesehatan manusia maupun bagi kesetimbangan lingkungan hidup.

\section{Besi (Fe) di Lingkungan Perairan}

Besi dalam air berbentuk ion bervalensi dua $\left(\mathrm{Fe}^{2+}\right)$ dan bervalensi tiga $\left(\mathrm{Fe}^{3+}\right)$, tergantung kondisi $\mathrm{pH}$ dan oksigen terlarut dalam air. Dalam bentuk ikatan dapat berupa $\mathrm{Fe}_{2} \mathrm{O}_{3}, \mathrm{Fe}(\mathrm{OH})_{2}, \mathrm{Fe}(\mathrm{OH})_{3}$ atau $\mathrm{FeSO}_{4}$ tergantung dari unsur lain yang mengikatnya. Besi dalam air bersumber dari dalam tanah sendiri di samping dapat pula berasal dari sumber lain, diantaranya dari larutnya pipa besi, reservoir air dari besi atau endapan - endapan buangan industri. Pada air permukaan jarang ditemui kadar Fe > 12 mg/l, tapi dalam air tanah kadar Fe dapat jauh lebih tinggi. Pada air yang tidak mengandung $\mathrm{O}_{2}$ seperti air tanah, sering kali berada sebagai $\mathrm{Fe}^{2+}$ teroksidasi menjadi $\mathrm{Fe}^{3+} . \mathrm{Fe}^{3+}$ sulit larut pada $\mathrm{pH}$ 6-8, dapat menjadi ferihidroksida atau salah satu jenis oksida yang merupakan zat padat dan bisa mengendap. Dalam air sungai besi berada sebagai $\mathrm{Fe}^{2+}, \mathrm{Fe}^{3+}$ terlarut dan $\mathrm{Fe}^{3+}$ dalam bentuk senyawa organis berupa koloid. Pada perairan alami dengan $\mathrm{pH}$ sekitar 7 dan kadar oksigen terlarut yang cukup, ion ferro yang bersifat mudah larut dioksidasi menjadi ion ferri. Pada oksidasi ini terjadi pelepasan elektron. Sebaliknya. pada reduksi ferri menjadi ferro terjadi penangkapan elektron. Proses oksidasi dan reduksi besi tidak melibatkan oksigen dan hidrogen (Eckenfelder, 1989).

Pada $\mathrm{pH}$ sekitar 7,5 - 7,7 ion ferri mengalami oksidasi dan berikatan dengan hidroksida membentuk $\mathrm{Fe}(\mathrm{OH})_{3}$ yang bersifat tidak larut dan mengendap (presipitasi) di dasar perairan, membentuk warna kemerahan pada substrat dasar. Oleh karena itu, besi hanya ditemukan pada perairan yang berada dalam kondisi anaerob (anoksik) dan suasana asam (Cole, 1988 dalam Sembiring, 2010). Fenomena serupa terjadi pada badan sungai yang menerima aliran air asam dengan kandungan besi (ferro) cukup tinggi. Sebagai petanda terjadinya pemulihan (recovery) kualitas air, pada bagian hilir sungai dasar perairan berwarna kemerahan karena terbentuknya $\mathrm{Fe}(\mathrm{OH})_{3}$ sebagai konsekuensi dari meningkatnya $\mathrm{pH}$ dan terjadinya proses oksidasi besi (ferro) (Cole, 1988 dalam Sembiring 2010). Perairan alam, besi berikatan dengan anion membentuk senyawa $\mathrm{FeCl}_{2}, \mathrm{Fe}\left(\mathrm{HCO}_{3}\right)$, dan $\mathrm{Fe}\left(\mathrm{SO}_{4}\right)$. Pada perairan yang diperuntukkan 
bagi keperluan domestik, pengendapan ion ferri dapat mengakibatkan wama kemerahan pada porselin, bak mandi, pipa air, dan pakaian. Kelarutan besi meningkat dengan menurunnya $\mathrm{pH}$.

\section{Seng (Zn) di Lingkungan Perairan}

Masuknya Zn ke sungai sebagai akibat dari limpasan air permukaan tanah yang umumnya disebabkan oleh hujan. Untuk Zn yang berasal dari adisi limbah industri, umumnya terdapat dalam bentuk sphalerite $(\mathrm{ZnS})$ dan smithsonite $\left(\mathrm{ZnCO}_{3}\right)$. Sekitar $3 / 4$ dari total $\mathrm{Zn}$ diperoleh dari pembentukan logam dan masing - masing komponen Zn tergantung jenis industrinya. Hutagalung (1984) menyatakan bahwa sumber logam $\mathrm{Zn}$ di perairan berasal dari material geokimia yang terbawa atau ada pada sungai, bahan baku minyak, besi, cat dan sisa-sisa kaleng bekas. Pada industri tekstil, logam seng dapat berfungsi sebagai bahan kimia tambahan pada proses penyempurnaan akhir juga untuk pengawetan serat khususnya anti jamur (fungisida) dan insektisida. Logam seng juga merupakan bagian dari penyusun zat warna tekstil terutama zat warna dari komplek logam dan pigmen.

Menurut Hutagalung (1984), logam yang masuk ke perairan akan mengalami pengenceran, pengendapan dan dispersi. Rendahnya kandungan logam $\mathrm{Zn}$ di perairan kemungkinan disebabkan oleh sifat logam Zn dalam lingkungan perairan dan sangat dipengaruhi oleh bentuk senyawanya. Effendi (2003) menyatakan bahwa logam Zn di perairan umumnya berbentuk persenyawaan sphalerite (ZnS), calamine $\left(\mathrm{ZnCO}_{3}\right)$, oksida seng $(\mathrm{ZnO})$ dan milemite $\left(\mathrm{Zn}_{2} \mathrm{SiO}_{4}\right)$. Kelarutan logam $\mathrm{Zn}$ dalam air relatif rendah, logam $\mathrm{Zn}$ dengan gugusan klorida dan sulfat mudah terlarut ke dalam sedimen, sehingga logam Zn di perairan banyak mengendap di dasar. Menurut Bryan dalam Efendi (2000) bahwa pengendapan logam di perairan terjadi karena adanya anion karbonat, hydroksil dan khlorida.

Metode Elektrokimia (Johanes, 1978)

Metode elektrokimia merupakan suatu proses kontinyu menggunakan arus listrik searah melalui peristiwa elektrokimia, yaitu gejala dekomposisi elektrolit dimana salah satu elektrodanya adalah logam. Reaksi kimia yang terjadi pada proses metode elektrokimia yaitu reaksi reduksi oksidasi, sebagai akibat adanya arus listrik (DC). Pada reaksi ini terjadi pergerakan dari ion-ion yaitu ion positif (kation) yang bergerak pada katoda yang bermuatan negatif. Sedangkan ion-ion negatif bergerak menuju anoda yang bermuatan positif yang kemudian ion-ion tersebut dinamakan sebagai anion (bermuatan negatif). Dalam proses ini akan terjadi proses reaksi reduksi dimana logam-logam akan direduksi dan diendapkan di kutub negatif, sedangkan elektroda positif akan teroksidasi menjadi logam hidroksida yang berfungsi sebagai koagulan. Elektroda dalam proses metode elektrokimia merupakan salah satu alat untuk menghantarkan atau menyampaikan arus listrik ke dalam larutan agar larutan tersebut terjadi suatu reaksi (perubahan kimia). Elektroda tempat terjadi reaksi reduksi disebut katoda, sedangkan tempat terjadinya reaksi oksidasi disebut anoda. Reaksi yang terjadi pada elektroda tersebut sebagai berikut :

Reaksi pada Katoda (Johanes, 1978).

Pada katoda akan terjadi reaksi-reaksi reduksi terhadap kation, yang termasuk dalam kation ini adalah ion $\mathrm{H}^{+}$dan ion ion logam.

1. Ion $\mathrm{H}^{+}$dari suatu asam akan direduksi menjadi gas hidrogen yang akan bebas sebagai gelembunggelembung gas.

$$
2 \mathrm{H}^{+}+2 \mathrm{e}---\rightarrow \mathrm{H}_{2}
$$

2. Jika larutan mengandung ion-ion logam alkali, alkali tanah maka ion-ion ini tidak dapat direduksi dari larutan yang mengalami reduksi adalah pelarut (air) dan terbentuk gas hidrogen $\left(\mathrm{H}_{2}\right)$ pada katoda.

$$
2 \mathrm{H}_{2} \mathrm{O}+2 \mathrm{e} \quad-----\rightarrow 2 \mathrm{OH}^{-}+\mathrm{H}_{2}
$$


Dari daftar Eo (deret potensial logam/deret volta), maka akan diketahui bahwa reduksi terhadap air limbah lebih mudah berlangsung dari pada reduksi terhadap pelarutnya (air). $\mathrm{K}, \mathrm{Ba}, \mathrm{Ca}, \mathrm{Na}, \mathrm{Mg}$, $\mathrm{Al}, \mathrm{Zn}, \mathrm{Cr}, \mathrm{Fe}, \mathrm{Cd}, \mathrm{Co}, \mathrm{Ni}, \mathrm{Sn}, \mathrm{Pb}, \mathrm{Sb}, \mathrm{Bi}, \mathrm{Cu}, \mathrm{Hg}, \mathrm{Ag}, \mathrm{Pt}, \mathrm{Au}$

3. Jika larutan mengandung ion-ion logam lain, maka ion-ion logam akan direduksi menjadi logamnya dan terdapat pada batang katoda.

Reaksi pada Anoda (Johanes, 1978).

1. Jika anoda yang digunakan logam aluminium yang akan teroksidasi

$$
\mathrm{Al}^{3+}+3 \mathrm{H}_{2} \mathrm{O} \quad-------\rightarrow \quad \mathrm{Al}(\mathrm{OH})_{3}+3 \mathrm{H}^{-}+3 \mathrm{e}
$$

2. Ion $\mathrm{OH}^{-}$dari basa akan mengalami oksidasi membentuk gas oksigen $\left(\mathrm{O}_{2}\right)$

$$
4 \mathrm{OH}^{-}----\rightarrow 2 \mathrm{H}_{2} \mathrm{O}+\mathrm{O}_{2}+4 \mathrm{e}
$$

3. Anion-anion lain $\left(\mathrm{SO}_{4}{ }^{2-}, \mathrm{SO}_{3}{ }^{2-}\right)$ tidak dapat dioksidasi dari larutan, yang akan mengalami oksidasi adalah pelarutnya $\left(\mathrm{H}_{2} \mathrm{O}\right)$ membentuk gas oksigen $\left(\mathrm{O}_{2}\right)$ pada anoda:

$$
2 \mathrm{H}_{2} \mathrm{O}-----\rightarrow 4 \mathrm{H}^{-}+\mathrm{O}_{2}+4 \mathrm{e}
$$

Dari reaksi-reaksi yang terjadi dalam proses metode elektrokimia maka pada katoda akan dihasilkan gas hidrogen dan reaksi ion logamnya. Sedang pada anoda akan dihasilkan gas halogen dan pengendapan flok-flok yang terbentuk. Proses metode elektrokimia dilakukan pada bejana elektrolisis yang di dalamnya terdapat katoda dan anoda sebagai penghantar arus listrik searah yang disebut elektroda, yang tercelup dalam larutan limbah sebagai elektrolit. Karena dalam proses metode elektrokimia ini menghasilkan gas yang berupa gelembung-gelembung gas maka kotoran-kotoran yang terbentuk yang ada dalam air akan terangkat ke atas permukaan air. Flok-flok terbentuk ternyata mempunyai ukuran yang relatif kecil dan lama kelamaan akan bertambah besar ukurannya (Riyanto,2013).

\section{METODOLOGI PENELITIAN}

\section{Bahan dan Alat}

Bahan utama yang digunakan dalam penelitian adalah limbah cair kerajinan tenun songket di kawasan Kertapati, Palembang. Alat yang digunakan adalah beker glass, kabel sumber arus DC, stopwatch, statif, penjepit kabel untuk lempengan katoda dan anoda.

\section{Prosedur}

Penelitian ini dilakukan dalam skala lab secara batch. Sampel limbah cair industri tenun songket dalam beker glass sebanyak 1 liter dialiri arus listrik 0,5A, tegangan 12 volt dengan waktu proses 20, 30, 40,50 dan 60 menit. Lempengan yang digunakan sebagai elektroda adalah aluminium masing-masing berukuran 24, 32 dan $40 \mathrm{~cm}$, jarak antar lempengan $5 \mathrm{~cm}$. Dari reaksi tersebut akan menghasilkan gas, buih dan flok $\mathrm{Al}(\mathrm{OH})_{3}$. Selanjutnya flok yang dihasilkan akan mengikat logam $\mathrm{Zn}$ dan Fe yang terdapat dalam limbah cair sehingga flok akan mengendap. Selanjutnya flok yang telah mengikat kontaminan $\mathrm{Zn}$ dan Fe diendapkan selama 30 menit dan sisa buih dipisahkan. Karakteristik proses elektrokimia pada penelitian ini ditentukan dengan mengukur kadar Zn dan Fe. Analisa kadar Fe dilakukan dengan metode pemeriksaan SNI 06-6989.4:2009 sedangkan Zn dengan metode pemeriksaan SNI 06-6989.7:2009. 


\section{HASIL DAN PEMBAHASAN}

Apabila dalam suatu elektrolit ditempatkan dua elektrode dan dialiri arus listrik searah maka akan terjadi proses elektrokimia, yaitu dekomposisi elektrolit. Ion positif akan bergerak ke katoda menerima elektron yang direduksi dan ion negatif akan bergerak ke anoda dan menyerahkan elektron yang dioksidasi. Proses elektrokimia pada penelitian ini menyebabkan terjadinya pelepasan ion $\mathrm{Al}^{3+}$ dari lempengan elektroda (anoda) dan akan mengikat ion $(\mathrm{OH})^{-}$membentuk flok $\mathrm{Al}(\mathrm{OH})_{3}$ yang akan mengikat kontaminan dan partikel-partikel dalam limbah cair. Pada katoda larutan yang mengalami reduksi adalah pelarut (air) dan terbentuk gas hidrogen $\left(\mathrm{H}_{2}\right)$ pada katoda (Hari dkk, 2010) :

$$
2 \mathrm{H}_{2} \mathrm{O}+2 \mathrm{e} \longrightarrow 2 \mathrm{OH}^{-}+\mathrm{H}_{2}
$$

Anoda terbuat dari logam almunium yang akan teroksidasi menjadi :

$$
\mathrm{Al}^{3+}+3 \mathrm{H}_{2} \mathrm{O} \longrightarrow \mathrm{Al}(\mathrm{OH})_{3}+3 \mathrm{H}^{+}+3 \mathrm{e}
$$

Ion $\mathrm{OH}^{-}$dari basa akan mengalami oksidasi membentuk gas oksigen $\left(\mathrm{O}_{2}\right)$ :

$$
4 \mathrm{OH}^{-} \longrightarrow 2 \mathrm{H}_{2} \mathrm{O}+\mathrm{O}_{2}+4 \mathrm{e}
$$

Ion aluminium yang dihasilkan dari reaksi anoda bereaksi dengan ion hidroksil membentuk aluminium hidroksida $\mathrm{Al}(\mathrm{OH})_{3}$ yang bersifat gel, yang dapat mengkoagulasi logam $\mathrm{Zn}$ dan Fe dari larutan secara adsorpsi. (Mohammed, 2007). Gas hidrogen dari katoda membantu flok $\mathrm{Al}(\mathrm{OH})_{3}$ dalam larutan yang terangkat ke permukaan. Ion aluminium yang dilepaskan dari anoda kemungkinan langsung berinteraksi dengan logam $\mathrm{Zn}$ dan Fe kemudian mengendap dalam bentuk garam tidak larut antara lain aluminium triphenolate $\left[\mathrm{Al}(\mathrm{OAr})_{3}\right]$ (Weeracai et al, 2002). Mekanisme pengendapan flok $\mathrm{Al}(\mathrm{OH})_{3}$ mengikuti prinsip koagulasi-flokulasi karena adanya pertumbuhan massa flok sehingga berat jenis flok menjadi besar dan akhirnya mengendap. Kondisi ini yang memungkinkan terjadinya penurunan kadar logam $\mathrm{Zn}$ dan $\mathrm{Fe}$ dalam limbah. Pembentukan endapan dan flok-flok yang terapung mengindikasikan bahwa $\mathrm{Al}(\mathrm{OH})_{3}$ mengikat polutan atau pengotor dengan efektif. Analisa kadar logam $\mathrm{Zn}$ dan Fe dalam limbah

\begin{tabular}{|c|c|c|c|c|c|}
\hline $\begin{array}{c}\text { Ukuran } \\
\text { lempengan } \\
\left(\mathrm{cm}^{2}\right)\end{array}$ & $\begin{array}{l}\text { Waktu } \\
\text { (menit) }\end{array}$ & $\begin{array}{c}\text { Konsentrasi } \\
\text { Zn (mg/l) }\end{array}$ & $\begin{array}{c}\text { Penurunan } \\
\text { konsentrasi } \mathrm{Zn} \\
(\%)\end{array}$ & $\begin{array}{c}\text { Konsentrasi } \\
\text { Fe (mg/l) }\end{array}$ & $\begin{array}{c}\text { Penurunan } \\
\text { konsentrasi } \\
\text { Fe }(\%)\end{array}$ \\
\hline \multirow{6}{*}{24} & 0 & 1.02 & 0 & 2.56 & 0 \\
\hline & 20 & 0.36 & 64.71 & 0.56 & 78.13 \\
\hline & 30 & 0.33 & 67.65 & 0.44 & 82.81 \\
\hline & 40 & 0.30 & 70.59 & 0.39 & 84.77 \\
\hline & 50 & 0.30 & 70.59 & 0.22 & 91.41 \\
\hline & 60 & 0.28 & 72.55 & 0.18 & 92.97 \\
\hline \multirow{6}{*}{32} & 0 & 1.02 & 0 & 2.56 & 0 \\
\hline & 20 & 0.12 & 88.24 & 0.49 & 80.86 \\
\hline & 30 & 0.10 & 90.20 & 0.35 & 86.33 \\
\hline & 40 & 0.08 & 92.16 & 0.31 & 87.89 \\
\hline & 50 & 0.07 & 93.14 & 0.28 & 89.06 \\
\hline & 60 & 0.04 & 96.08 & 0.20 & 92.19 \\
\hline \multirow{6}{*}{40} & 0 & 1.02 & 0 & 2.56 & 0 \\
\hline & 20 & 0.09 & 91.18 & 0.46 & 82.03 \\
\hline & 30 & 0.08 & 92.16 & 0.41 & 83.98 \\
\hline & 40 & 0.03 & 97.06 & 0.29 & 88.67 \\
\hline & 50 & 0.03 & 97.06 & 0.21 & 91.80 \\
\hline & 60 & 0.02 & 98.04 & 0.15 & 94.14 \\
\hline
\end{tabular}
sebelum diolah dengan metode elektrokimia masing-masing $1.02 \mathrm{mg} / \mathrm{L}$ dan $2.56 \mathrm{mg} / \mathrm{L}$.

Tabel 1. Hasil analisa kadar logam Zn dan Fe dan persentasi penurunan untuk tiap perlakuan 


\section{Hasil analisa kadar Zn}

Hasil analisis limbah cair kerajinan tenun songket setelah melalui proses elektrokimia dengan elektroda Al menunjukkan perubahan kadar Zn yang signifikan. Analisa awal limbah sebelum pengolahan kadar $\mathrm{Zn}$ adalah $1.02 \mathrm{mg} / \mathrm{L}$. Data pada Tabel 1 menunjukan bahwa luas lempengan dan waktu proses berpengaruh terhadap penurunan kadar Zn dalam limbah cair. Semakin luas permukaan lempengan yang digunakan dan semakin lama waktu proses maka penurunan kadar Zn makin besar. Hal ini disebabkan variasi waktu dan ukuran lempengan elektroda mempengaruhi banyak ion $\mathrm{Al}^{3+}$ yang terlarut. $\mathrm{Al}$ terlarut berperan sebagai koagulan yang berfungsi sebagai pembentuk flok $\mathrm{Al}(\mathrm{OH})_{3}$ untuk mengikat kontaminan dan partikel-partikel dalam limbah.

Data Tabel 1 menunjukkan pada ukuran lempengan $24 \mathrm{~cm}^{2}$ dan lama proses 20 - 60 menit kadar Zn yaitu $0.36-0.28 \mathrm{mg} / \mathrm{l}$, terjadi penurunan $64.71-72.55 \%$. Penggunaan lempengan berukuran $32 \mathrm{~cm}^{2}$ menghasilkan kadar Zn $0.12-0.04 \mathrm{mg} / \mathrm{l}$ dan penurunan yang dicapai 88.24 - $96.08 \%$ dalam waktu 20 - 60 menit. Kadar Zn 0.09 - 0.02 mg/l dengan penurunan 91.18 - $98.04 \%$ dihasilkan pada pemakaian lempengan berukuran $40 \mathrm{~cm}^{2}$ dalam waktu 20 - 60 menit. Pada penelitian ini penurunan terbesar kadar $\mathrm{Zn}$ dalam limbah terjadi pada waktu proses 60 menit dan ukuran lempengan elektroda $\mathrm{Al} 40 \mathrm{~cm}^{2}$ yaitu menghasilkan penurunan kadar Zn sebesar 98,04 \% dengan hasil 0.02 mg/l.

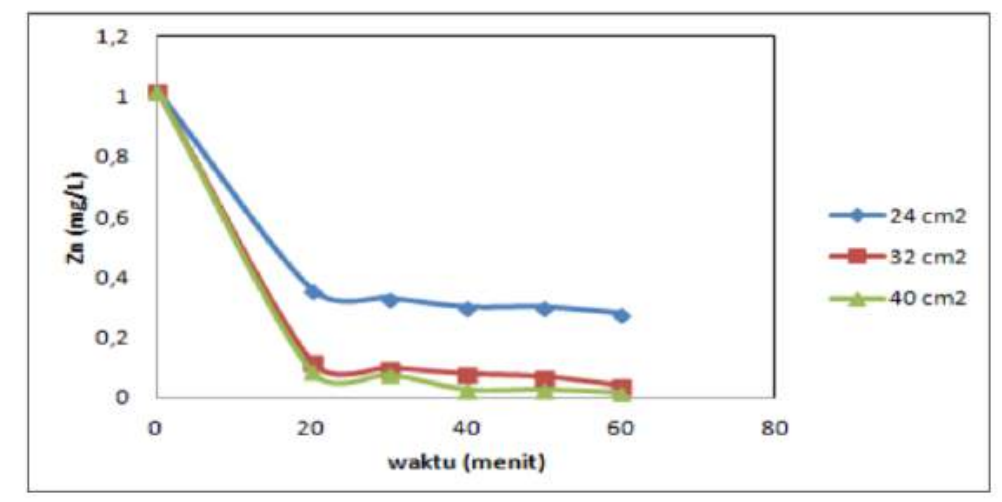

\section{Gambar 1. Grafik hubungan konsentrasi Zn dan waktu pada tiap ukuran lempengan Al}

\section{Hasil analisa kadar Fe}

Hasil analisis limbah cair kerajinan tenun songket setelah melalui proses elektrokimia dengan elektroda Al menunjukkan perubahan kadar Fe yang signifikan. Analisa awal limbah sebelum pengolahan kadar $\mathrm{Fe}$ adalah $2.56 \mathrm{mg} / \mathrm{L}$. Data pada Tabel 1 menunjukan bahwa luas lempengan dan waktu proses berpengaruh terhadap penurunan kadar Fe. Semakin luas permukaan lempengan yang digunakan dan semakin lama waktu proses maka penurunan kadar Fe makin besar. Hal ini disebabkan variasi waktu dan ukuran lempengan elektroda mempengaruhi banyak ion $\mathrm{Al}^{3+}$ yang terlarut. $\mathrm{Al}$ terlarut berperan sebagai koagulan yang berfungsi sebagai pembentuk flok $\mathrm{Al}(\mathrm{OH})_{3}$ untuk mengikat kontaminan dan partikel-partikel dalam limbah.

Data Tabel 1 menunjukkan pada ukuran lempengan $24 \mathrm{~cm}^{2}$ dan lama proses 20 - 60 menit kadar Fe yaitu $0.56-0.18 \mathrm{mg} / \mathrm{l}$, terjadi penurunan $78.13-92.97 \%$. Penggunaan lempengan berukuran $32 \mathrm{~cm}^{2}$ menghasilkan kadar Fe $0.49-0.20 \mathrm{mg} / \mathrm{l}$ dan penurunan yang dicapai $80.86-92.19 \%$ dalam waktu 20 - 60 menit. Kadar Fe 0.46 - 0.15 mg/l dengan penurunan 82.03 - $94.14 \%$ dihasilkan pada pemakaian lempengan ukuran $40 \mathrm{~cm}^{2}$ dalam waktu 20 - 60 menit. Pada penelitian ini penurunan terbesar kadar Fe 
dalam limbah terjadi pada waktu proses 60 menit dan ukuran lempengan elektroda $\mathrm{Al} 40 \mathrm{~cm}^{2}$ yaitu menghasilkan penurunan kadar Fe sebesar 94,14 \% dengan hasil $0.15 \mathrm{mg} / \mathrm{l}$.

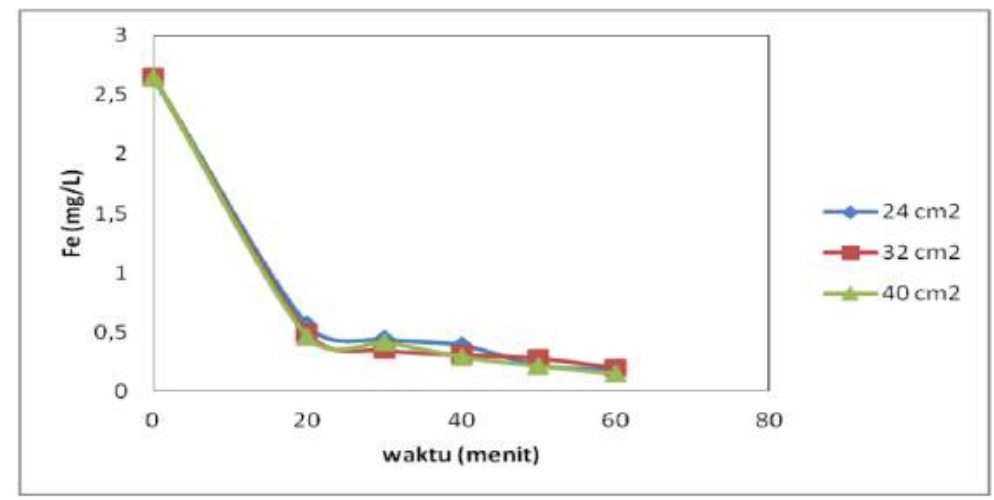

\section{Gambar 2. Grafik hubungan kadar Fe dan waktu pada tiap ukuran lempengan $\mathrm{Al}$}

Dari Gambar 1 dan 2 terlihat bahwa waktu proses berpengaruh kepada penurunan kadar Zn dan Fe. Hal ini terjadi karena semakin lama waktu yang digunakan pada proses elektrokimia semakin banyak ion $\mathrm{Al}^{3+}$ terlarut dan gas hidrogen yang terbentuk. Al terlarut berperan sebagai koagulan yang berfungsi sebagai pembentuk flok $\mathrm{Al}(\mathrm{OH})_{3}$ untuk mengikat kontaminan dan partikel-partikel dalam limbah. Luas lempengan elektroda memberikan pengaruh namun tidak terlalu signifikan.

Penurunan kadar Zn dan Fe terlihat sangat signifikan terjadi pada waktu proses 20 menit. Hasil analisa kadar Zn dan Fe untuk proses elektrokimia 30, 40, 50 dan 60 menit menunjukan kecenderungan untuk terus turun tetapi perbedaannya tidak terlalu besar. Saat lempengan elektroda sudah jenuh dan medan magnet yang terjadi sudah sangat kecil maka proses elektrokimia sudah minimum dan proses koagulasi tidak terjadi sehingga kadar $\mathrm{Zn}$ dan Fe dalam limbah akan tetap. Proses elektrokimia mencapai titik terendah pada saat lempengan elektroda tidak menimbulkan medan magnet (Susetyaningsih, 2008). Dari penelitian yang telah dilakukan diperoleh data bahwa perbedaan ukuran elektroda dan waktu proses akan menghasilkan penurunan kadar Zn dan Fe yang berbeda. Dari grafik terlihat bahwa semakin lama waktu proses elektrokimia dan semakin besar ukuran lempeng semakin besar penurunan kadar $\mathrm{Zn}$ dan Fe.

\section{KESIMPULAN}

Hasil penelitian ini memberikan kesimpulan bahwa proses elektrokimia mampu menurunkan kadar logam $\mathrm{Zn}$ dan Fe dalam limbah cair kerajinan tenun songket. Kondisi terbaik dicapai pada waktu proses 60 menit dan luas lempengan elektroda $40 \mathrm{~cm}^{2}$ dimana penurunan kadar Zn sebesar $98.04 \%$ dengan $0.02 \mathrm{mg} / \mathrm{L}$ Zn yang masih ada dalam limbah. Penurunan logam Fe sebanyak $94.14 \%$ dengan kadar 0.15 $\mathrm{mg} / \mathrm{L}$ juga dicapai dengan kondisi yang sama. Dengan demikian limbah cair ini sudah cukup aman untuk dialirkan ke badan sungai.

\section{DAFTAR PUSTAKA}

Eckenfelder, W, Wesley. (2000) Water Pollution Control. Third Edition. Mc Graw Hill International Edition. New York.

Effendi, H. (2000) Telaah Kualitas Air. IPB. Bogor. 
Effendi, H.(2003) Telaah Kualitas Air bagi Pengelolaan Sumber Daya Alam dan Lingkungan Perairan. Kanisius. Yogyakarta.

Hari P, Bambang, Harsanti, Mining. (2010) Pengolahan Limbah Cair Tekstil Menggunakan Metode Elektrokimia dengan Sel Al-Al. Prosiding Seminar Nasional Teknik Kimia "Kejuangan". Yogyakarta, 26 Januari 2010.

Hutagalung, H.P.(1984) Logam Berat dalam Lingkungan Laut. Oseana. Vol IX LP3O-LIPI. Jakarta.

Johanes, H. (1978) Listrik dan Magnet. Balai Pustaka. Jakarta.

Mohammed, Ahmed A. (2007) Electrocoagulation of Phenol for Wastewater Treatment Iraqi Journal of Chemical and Petroleum Engineering. Vol.9 No.3 .ISSN: 1997-4884

Sembiring, T (2010) Efek Besi di dalam Air. USU Institutional Repository. Medan.

Weerachai, P.,Sombat,C and Duang,B. (2002) Electrocoagulation and Subsequent Recovery of Phenolic Compounds. Japan Society for Analytical Chemistry. October Vol 16. 